\title{
CORRELATES OF SMOKING WITH SOCIOECONOMIC STATUS, LEISURE TIME PHYSICAL ACTIVITY AND ALCOHOL CONSUMPTION AMONG POLISH ADULTS FROM RANDOMLY SELECTED REGIONS
}

\author{
Donata Woitas-Ślubowska ${ }^{1}$ Elżbieta Hurnik ${ }^{2}$, Anna Skarpańska-Stejnborn ${ }^{1}$ \\ 1 University School of Physical Education in Poznań, The Branch Faculty of Physical Culture in Gorzów Wlkp. Poland \\ ${ }^{2}$ University School of Physical Education in Poznań, Computing and ITCentre, Poland
}

\section{SUMMARY}

Aim: To determine the association between smoking status and leisure time physical activity (LTPA), alcohol consumption, and socioeconomic status (SES) among Polish adults.

Material and methods: 466 randomly selected men and women (aged 18-66 years) responded to an anonymous questionnaire regarding smoking, alcohol consumption, LTPA, and SES. Multiple logistic regression was used to examine the association of smoking status with six socioeconomic measures, level of LTPA, and frequency and type of alcohol consumed. Smokers were defined as individuals smoking occasionally or daily.

Results: The odds of being smoker were 9 times (men) and 27 times (women) higher among respondents who drink alcohol several times/ week or everyday in comparison to non-drinkers $(p<0.0001$ and $p<0.0001)$. Among men with the elementary/vocational level of education the frequency of smoking was four times higher compared to those with the high educational attainment $(p=0.007)$. Among women we observed that students were the most frequent smokers. Female students were almost three times more likely to smoke than non-professional women, and two times more likely than physical workers $(p=0.018)$.

Conclusion: The findings of this study indicated that among randomly selected Polish man and women aged 18-66 smoking and alcohol consumption tended to cluster. These results imply that intervention strategies need to target multiple risk factors simultaneously. The highest risk of smoking was observed among low educated men, female students, and both men and women drinking alcohol several times a week or every day. Information on subgroups with the high risk of smoking will help in planning future preventive strategies.

Key words: smoking, alcohol consumption, leisure time physical activity, socioeconomic status, adults

Address for correspondence: D. Woitas-Ślubowska, The Branch Faculty of Physical Culture, Ul. Estkowskiego 13, 66-400 Gorzów Wlkp., Poland. E-mail: donataws@op.pl

\section{INTRODUCTION}

Smoking is associated with increased incidences of various forms of cancer, coronary heart disease, and stroke, and is the leading cause of chronic obstructive pulmonary disease (1). A previous study documents that behavioural risk factors associated with smoking significantly increase the risk of harm to smokers' health (2). Some unhealthy behaviours may even work together to produce a greater risk than if the individual risks were simply added together $(3,4)$.

Smoking is one of the greatest public health concerns in European countries because its health consequences and large prevalence (5). Statistical data for 1986-88 show that Poland has the highest level of cigarette consumption among East European countries (6), and that the population of Polish middle aged men has the highest proportions of death attributed to tobacco use $(50 \%)(7)$. Between 1996 and 2004 a reduction in the number of smokers could be observed in Poland, but the percentage of daily smokers remains still high (33,9\% men and $19,3 \%$ women) (8).
Studies of the relationships between smoking and socioeconomic factors show that in many countries the population groups at high risk of smoking are males, and people of young age, low income, and low educational status (9-14).

However, the results of research on the relationship between smoking status and other unhealthy behaviours, such as low level of leisure time physical activities (LTPA) and high alcohol consumption, are not clear. Several cross-sectional studies confirm a weak inverse relationship between LTPA and smoking $(10,15$, 16). A review of over 50 articles reporting empirical relationships between smoking and physical activity shows that almost $60 \%$ of the studies reported a definitely negative association, but that relationship was often attenuated or reversed among adolescents and males and for moderate (vs. vigorous) exercise (17). Smoking men and women are characterized not only by lower LTPA, but also by increased frequency and amount of alcohol consumption compared to non-smokers $(9,10)$. However, the relationship between smoking and alcohol consumption is not confirmed in other study (18). 
The results of studies of the correlates of smoking are ambiguous and incomplete, therefore further research is needed. Better understanding is required as a basis for epidemiological studies and for planning interventions to correct the correlated behaviours.

In this study we estimated the risk of smoking among Polish men and women depending on socioeconomic status (SES), engagement in LTPA, and alcohol consumption. Further, we determined which of these variables are independent risk factors of smoking among adults.

\section{MATERIALS AND METHODS}

\section{Subjects and Questionnaire}

Studies were conducted in Poland in the spring/summer season of 2004. The target sample was determined in a two-stage drawing of lots. In the first stage, lots were drawn for provinces. In the second stage, the sample was randomly selected from telephone directories for the three earlier drawn provinces. Anonymous questionnaires with self-addressed stamped envelopes were mailed to 888 persons. The overall response rate was $52.5 \%$ $(n=467)$. One questionnaire was uncomplete and was therefore excluded from further analysis. A total of 466 questionnaires (231 answered by women, and 235 by men) qualified for the analysis.

The questionnaire comprised questions regarding the healthrelated behaviours and SES. All data collected in the study were self-reported by the subjects. This article is based on data regarding the SES, tobacco and alcohol consumption, and engagement in LTPA.

\section{Measures}

\section{Smoking}

Respondents were asked: Could you say that within the last 30 days: you did not smoke, you smoked occasionally (not every day), you smoked 1-10 cigarettes/day, you smoked more than 10 cigarettes/day?

\section{LTPA}

In order to estimate LTPA, the respondents recorded the duration and forms of LTPA during last week. Based on these data they were ranked in one out of three categories of LTPA:

I - sufficiently active: persons who reported recommended level of leisure time physical activity, meaning at least 30 minutes of moderate physical activity five or more days per week (e.g. walking, bicycling, light gardening) or at least 20 minutes of vigorous physical activity three or more days per week (e.g. jogging and other recreational sports or heavy gardening) (19),

II - insufficiently active: persons who reported leisure time physical activity during the week that was less than recommended level (19), but greater than none,

III - inactive: persons who reported no leisure time physical activity during the last week.

\section{Alcohol Consumption}

The measures of alcohol consumption were as follow:

- frequency of alcohol consumption within the last six months (categories: I did not drink alcohol; I drank alcohol less than once a month; I drank alcohol once a month to once a week; I drank alcohol several times a week or every day).

- the type of alcohol consumed within the last six months (categories: I did not drink alcohol; I drank only beer; I drank low-alcohol drinks: beer, wine, liqueurs; I drank various alcoholic drinks, including spirits).

\section{Socioeconomic Status}

The following characteristics were taken into consideration: gender, age, area of residence, marital status, educational level, net income in Polish zloty (PLN) per household member in the month prior to the survey, and occupation. The category "occupation" included: student, physical worker, white-collar worker, and non-professional (unemployed, pensioner and old-age pensioner, housewife, women on maternity leave).

\section{Statistical Analysis}

The gender differences in distribution of SES and health related behaviours were assessed using the two-side two-element structure test. The risk of smoking was identified during the logistic regression analysis, using the "smoking status" as the covariate. A dichotomy of (0) I smoked (occasionally or daily), and (1) I didn't smoke was defined. The independent variables were SES, level of LTPA, type of alcohol consumed, and frequency of alcohol consumption. All these variables were statistically significantly related to smoking status in the $\chi^{2}$ test analysis. For each independent variable we adopted a reference category and gave it value 1.0. At the first stage, crude odds ratios (CORs) and $95 \%$ confidence intervals (CIs) of the impact of odd of each independent variables on smoking were calculated. Subsequently, the multifactorial analysis, considering simultaneous effects of all variables on the risk of smoking was employed. Results of the multivariate analyses for the models are presented as odds ratios (ORs) and their 95\% confidence intervals. All p-values were twosided and $\mathrm{p}<0.05$ was defined as statistically significant. The statistical analyses were performed separately for men and women. Calculations were performed using Statistica 7.0 PL Software.

\section{RESULTS}

Distribution of socioeconomic status and behavioural risk factors by gender are presented in Table 1 . Women were better educated compared to men. More women attained secondary education and were less physically working, living in rural area, and having high income. The percentage of female inactive individuals, and daily smokers were lower among women than men. Furthermore, male and female subjects differed as to the kind and frequency of alcohol consumption.

In order to assess the relationships between smoking and other variables, logistic regression analysis was applied. Based on the crude examination increase of the risk of smoking among women was associated with older age and drinking alcohol several times/ week or everyday. Other relationships were not significant. After controlling for all variables, occupation and frequency of consumption of alcohol were shown as statistically significant factors ( $p=0.018$ and $p<0.0001$ respectively). The least risk of smoking was observed among non-professional women. In comparison 
Table 1. Distribution of socioeconomic status and behavioural risk factors by gender

\begin{tabular}{|c|c|c|c|c|c|c|}
\hline \multirow{2}{*}{ Variables } & \multirow{2}{*}{ Categories } & \multicolumn{2}{|c|}{ Females } & \multicolumn{2}{|c|}{ Males } & \multirow{2}{*}{$\mathrm{Pa}^{\mathrm{a}}$} \\
\hline & & N & $\%$ & N & $\%$ & \\
\hline \multirow{3}{*}{ Age (yrs) } & $18-34$ & 102 & 44.2 & 87 & 37.0 & 0.114 \\
\hline & $35-50$ & 71 & 30.7 & 71 & 30.2 & 0.907 \\
\hline & $51-66$ & 58 & 25.1 & 77 & 32.8 & 0.068 \\
\hline \multirow{3}{*}{ Education level } & Elementary or vocational & 51 & 22.1 & 81 & 34.5 & 0.009 \\
\hline & Secondary & 114 & 49.4 & 93 & 39.6 & 0.034 \\
\hline & Higher & 66 & 28.6 & 61 & 25.9 & 0.376 \\
\hline \multirow{4}{*}{ Occupation } & Student & 59 & 22.5 & 38 & 16.2 & 0.014 \\
\hline & Physical worker & 49 & 21.2 & 73 & 31.1 & 0.016 \\
\hline & White-collar worker & 77 & 33.3 & 64 & 27.2 & 0.152 \\
\hline & Non-professional & 44 & 19.0 & 60 & 25.5 & 0.092 \\
\hline \multirow{3}{*}{ Place of residence } & Rural area & 22 & 9.5 & 37 & 15.7 & 0.044 \\
\hline & Town & 137 & 59.3 & 122 & 51.9 & 0.109 \\
\hline & City & 70 & 30.3 & 71 & 30.2 & 0.981 \\
\hline \multirow{2}{*}{ Martial status } & Single, divorced, widowed & 120 & 51.9 & 108 & 46.0 & 0.203 \\
\hline & Married, living as married & 111 & 48.1 & 127 & 54.0 & 0.203 \\
\hline \multirow{4}{*}{ Income } & $\leq 300$ PLN & 25 & 10.8 & 20 & 8.5 & 0.401 \\
\hline & $301-600$ PLN & 122 & 52.8 & 123 & 52.3 & 0.914 \\
\hline & $601-900$ PLN & 57 & 24.7 & 52 & 22.1 & 0.501 \\
\hline & 901 PLN and more & 22 & 9.5 & 37 & 15.7 & 0.045 \\
\hline \multirow{3}{*}{ LTPA } & Inactive & 39 & 16.9 & 61 & 26.0 & 0.017 \\
\hline & Insufficiently active & 139 & 60.2 & 133 & 56.6 & 0.431 \\
\hline & Sufficiently active & 50 & 21.6 & 38 & 16.2 & 0.137 \\
\hline \multirow{4}{*}{ Smoking } & I did not smoke & 136 & 58.9 & 105 & 44.7 & 0.002 \\
\hline & I smoked occasionally & 63 & 27.3 & 48 & 20.4 & 0.081 \\
\hline & I smoked $\leq 10$ cigarettes/day & 23 & 10.0 & 52 & 22.1 & $<0.001$ \\
\hline & I smoked >10 cigarettes/day & 9 & 3.9 & 30 & 12.8 & $<0.001$ \\
\hline \multirow{4}{*}{$\begin{array}{l}\text { Type of alcohol } \\
\text { consumed }\end{array}$} & I did not drink alcohol & 55 & 23.8 & 25 & 10.6 & $<0.001$ \\
\hline & I drank only beer & 23 & 10.0 & 51 & 21.7 & $<0.001$ \\
\hline & I drank low-alcohol drinks & 79 & 34.2 & 38 & 16.2 & $<0.001$ \\
\hline & $\begin{array}{l}\text { I drank various alcoholic drinks, including } \\
\text { spirits }\end{array}$ & 74 & 32.0 & 121 & 51.5 & $<0.001$ \\
\hline \multirow{4}{*}{$\begin{array}{l}\text { Frequency } \\
\text { of alcohol } \\
\text { consumption }\end{array}$} & I did not drink alcohol & 51 & 22.1 & 25 & 10.6 & $<0.001$ \\
\hline & Once a month or less & 87 & 37.7 & 51 & 21.7 & $<0.001$ \\
\hline & Once a month to once a week & 78 & 33.8 & 109 & 46.4 & 0.006 \\
\hline & Several times a week and everyday & 14 & 6.1 & 48 & 20.4 & $<0.001$ \\
\hline
\end{tabular}

a $p$-value for the two-side two-element structure test

to these subjects, students were almost three times more likely to smoke, physical workers - almost two times, and white-collar workers -1.4 times (adjusted OR=2.78; 95\% CI 1.19-6.60, $\mathrm{OR}=1.98 ; 95 \%$ CI $1.13-3.48$, and $\mathrm{OR}=1.41 ; 95 \%$ CI $1.06-1.87$ respectively). The risk of smoking among those who drink alcohol several times/week or everyday, compared to women who do not drink, was higher by a factor of 27 (adjusted OR=26.96; 95\% CI 8.41-86.41) (Table 2).

Based on the crude examination the risk of smoking increases among low educated men and those who drink alcohol. Other relationships were not significant. After adjustment for all variables, education and the frequency of alcohol consumption re- 
Table 2. Association between smoking (vs. non-smoking) and socioeconomic, LTPA, and alcohol consumption: women and men

\begin{tabular}{|c|c|c|c|c|c|}
\hline \multirow{2}{*}{ Variables } & \multirow{2}{*}{ Categories } & \multicolumn{2}{|c|}{ Women } & \multicolumn{2}{|c|}{ Men } \\
\hline & & $\operatorname{COR}(95 \% \mathrm{Cl})^{\mathrm{a}}$ & $\mathrm{OR}(95 \% \mathrm{Cl})^{\mathrm{b}}$ & $\operatorname{COR}(95 \% \mathrm{Cl})^{\mathrm{a}}$ & $\mathrm{OR}(95 \% \mathrm{Cl})^{\mathrm{c}}$ \\
\hline \multirow{3}{*}{ Age categories } & $18-34$ & 1 & & 1 & \\
\hline & $35-50$ & $1.83(1.06-3.14)$ & & $1.47(0.91-2.38)$ & \\
\hline & $51-66$ & $\begin{array}{c}3.34(1.13-9,88) \\
p=0.029\end{array}$ & & $\begin{array}{c}2.17(0.84-5.64) \\
p=0.111\end{array}$ & \\
\hline \multirow{3}{*}{ Education } & Elementary/Vocational & 1 & & $4.28(1.12-16.39)$ & $4.10(1.91-36.26)$ \\
\hline & Secondary & $1.52(0.79-2.98)$ & & $1.82(1.04-2.54)$ & $1.90(1.17-2.45)$ \\
\hline & Higher & $\begin{array}{c}1.91(0.71-5.11) \\
p=0.203\end{array}$ & & $\begin{array}{c}1 \\
p=0.036\end{array}$ & $\begin{array}{c}1 \\
p=0.007\end{array}$ \\
\hline \multirow{4}{*}{ Occupation } & Student & $3.35(0.98-11.48)$ & $2.78(1.19-6.60)$ & 1 & \\
\hline & Physical worker & $2.24(0.99-5.09)$ & $1.98(1.13-3.48)$ & $1.12(0.78-1.60)$ & \\
\hline & White-collar worker & $1.50(0,99-2.26)$ & $1.41(1.06-1.87)$ & $1.25(0.61-2.55)$ & \\
\hline & Non-professional & $\begin{array}{c}1 \\
p=0.054\end{array}$ & $\begin{array}{c}1 \\
p=0.018\end{array}$ & $\begin{array}{c}1.40(0.48-4.08) \\
p=0.541\end{array}$ & \\
\hline \multirow{3}{*}{ Place of residence } & Rural & 1 & & 1 & \\
\hline & Town & $1.36(0.79-2.34)$ & & $1.16(0.71-1.90)$ & \\
\hline & City & $\begin{array}{c}1.84(0.62-5.47) \\
p=0.269\end{array}$ & & $\begin{array}{c}1.35(0.50-3.62) \\
p=0.552\end{array}$ & \\
\hline \multirow[b]{2}{*}{ Marital status } & Single, divorced, widowed & 1 & & 1 & \\
\hline & Married, living as married & $\begin{array}{c}0.62(0.29-1.33) \\
p=0.218\end{array}$ & & $\begin{array}{c}0.66(0.33-1.33) \\
p=0.246\end{array}$ & \\
\hline \multirow{4}{*}{ Income } & $\leq 300$ PLN & 1 & & 1 & \\
\hline & 300-600 PLN & $1.11(0.74-1.66)$ & & $0.96(0.66-1.40)$ & \\
\hline & $601-900$ PLN & $1.22(0.54-2.76)$ & & $0.93(0.44-1.97)$ & \\
\hline & 901 PLN and more & $\begin{array}{c}1.35(0.40-4.59) \\
p=0.624\end{array}$ & & $\begin{array}{c}0.90(0.29-2.76) \\
p=0.851\end{array}$ & \\
\hline \multirow{3}{*}{ Level of LTPA } & Inactive & 1 & & 1 & \\
\hline & Insufficiently active & $0.68(0.40-1.14)$ & & $0.72(0.44-1.16)$ & \\
\hline & Sufficiently active & $\begin{array}{c}0.46(0.16-1.31) \\
p=0.144\end{array}$ & & $\begin{array}{c}0.51(0.20-1.34) \\
p=0.172\end{array}$ & \\
\hline \multirow{4}{*}{ Type of alcohol consumed } & I did not drink alcohol & 1 & & 1 & \\
\hline & Only beer & $1.45(0,97-2.19)$ & & $1.07(0.77-1.47)$ & \\
\hline & Low-alcohol drinks & $2.11(0,93-4,78)$ & & $1.14(0.60-2.18)$ & \\
\hline & $\begin{array}{l}\text { Various alcoholic drinks, also } \\
\text { spirits }\end{array}$ & $\begin{array}{c}3.07(0.90-10.46) \\
p=0.073\end{array}$ & & $\begin{array}{c}1.22(0.46-3.21) \\
p=0.685\end{array}$ & \\
\hline \multirow{4}{*}{$\begin{array}{l}\text { Frequency of alcohol con- } \\
\text { sumption }\end{array}$} & I did not drink alcohol & 1 & 1 & 1 & 1 \\
\hline & Once a month or less & $2.25(1.34-3.78)$ & $3.00(2.04-4.42)$ & $2.13(1.43-3.18)$ & $2.10(1.51-2.93)$ \\
\hline & $1 /$ month to $1 /$ week & $5.07(1.80-14.29)$ & $8.99(4.14-19.54)$ & $4.54(2.04-10.11)$ & $4.43(2.28-8.58)$ \\
\hline & $\begin{array}{l}\text { Several times/week or every } \\
\text { day }\end{array}$ & $\begin{array}{c}11.43(2.42-54.03) \\
p=0.0023\end{array}$ & $\begin{array}{c}26.96(8.41-86.41) \\
p \leq 0.0001\end{array}$ & $\begin{array}{c}9.68(2.92-32.12) \\
p=0.0002\end{array}$ & $\begin{array}{c}9.31(3.45-25.14) \\
p \leq 0.0001\end{array}$ \\
\hline
\end{tabular}

a all variables in model

${ }^{\mathrm{b}}$ adjusted for income, place of residence, marital status, education, LTPA, age, and type of alcohol consumed (variables are listed in the order in which they were reduced from the model)

${ }^{c}$ adjusted for income, place of residence, type of alcohol consumed, occupation, martial status, LTPA, and age (variables are listed in the order in which they were reduced from the model)

mained significant factors ( $\mathrm{p}=0.007$ and $\mathrm{p}<0.0001$ respectively). Comparing the risk of smoking by level of education those with secondary and elementary, vocational level of education were at two times or four times higher risk respectively compared to those highly educated (adjusted OR=1.90; 95\% CI 1.17-2.45 and $\mathrm{OR}=4.10 ; 95 \%$ CI 1.91-36.26 respectively). Smoking was directly related to the frequency of alcohol consumption. The surveyed non-drinkers were at two-fold lower risk of smoking 
than those drinking once a month or less (adjusted $\mathrm{OR}=2.10$; 95\% CI 1.51-2.93), and at over nine-fold lower risk of smoking than those drinking several times a week or everyday (adjusted $\mathrm{OR}=9.31$; 95\% CI 3.45-25.14) (Table 2).

\section{DISCUSSION}

In the present study the daily smoking prevalence among men $(35 \%)$ was on similar level to the one observed in 2004 in a representative sample of Polish men (aged 15 yrs + ) (33.9\%) (8). The prevalence of smoking reported by men in this study is also similar to the results from Bulgarian population aged $18 \mathrm{yrs}+(38.4 \%)(20)$, and lower compared to the Baltic countries in which Estonian (47\%), Latvian (54\%), and Lithuanian $(46 \%)$ men were daily smokers (14). The prevalence of daily smoking among female subjects (14\%) was lower compared to representative sample of Polish women (19.3\%) (8), and lower than observed among Estonian (21\%), Latvian (19\%) (14), and Bulgarian women (16.7\%) (20), but higher than among Lithuanian women (11\%) (14).

The findings from this study support the hypotheses and the existing evidence that shows relationship between cigarette smoking and alcohol use. This relationship was observed among both men and women in the United States of America $(21,22)$, Basque Country (the North of Spain) (21), Finland (10), Poland (9), and among women in Australia (23). Moreover, the study conducted among Finish men and women shows that sociodemographic differences observed in the associations between smoking and alcohol consumption were few and the patterns of unhealthy behaviour were also remarkably similar in both genders. However, the prevalence of individual unhealthy behaviour is known to vary across sociodemographic categories as well as between men and women. Therefore, even if the associations between unhealthy behaviours were similar their significance may vary between population groups (10). In our study both male and female drinkers were more than non-drinkers likely to smoke, and the risk of smoking was higher for drinking women than men. The similar tendency was shown in previous study conducted among adults (25-64 yrs) in Łódź (Poland) (9).

Earlier published study documented that moderate alcohol consumption is associated with the highest odds of reporting above-average health status among adults, even after controlling for chronic health conditions and demographic and lifestyle factors associated with health (24). The study of men and women aged 35-69 years shows that moderate regular consumption of alcohol over five or six days a week is associated with reduction in risk of a major coronary event (25). Moderate alcohol consumption provided a protective effect from death from all causes combined, relative to nil or low consumption, and relative to heavy alcohol consumption (26). Mild to moderate alcohol consumption is associated with a lower prevalence of the metabolic syndrome, with a favorable influence on lipids, waist circumference, and fasting insulin. This association was strongest among beer and wine drinkers (27). However, according to other author, whether health benefits are associated with moderate alcohol consumption is a complex and controversial topic $(28,29)$. Documented in our study significant increase in risk of smoking among Polish adults drinking alcohol several times/week or every day suggests carefulness in recommendation on moderate drinking alcohol in prevention chronic diseases in certain subgroups or populations.

The results of our study reinforced the impression from previously published reports that smoking is associated with low level of LTPA $(30,31)$; however this relationship was not statistically significant in this study. Being inactive during leisure time was also not significantly associated with smoking among adults in a country in transition, Albania (32). An inverse, moderately strong or weak relationship between the smoking status and LTPA was found in the population of more than ten thousand university students in 21 European countries (30). A similar association was also documented among both men and women in representative sample, ages 25-69, in Germany (31), among men and women in Denmark (33) and Greece (34), in a cohort of Swedish men (35), and among Korean men (ages 18-74) (36). Although in many studies the inverse relationship between physical activity and smoking was true for both women and men, it was found to be stronger in men (37). In our study this tendency was also observed.

The results of the present study show that among Polish adults aged 18-66 years smoking and drinking alcohol, and smoking and inactivity (non significantly) cluster. Results from the studies of Finnish men, have suggested that accumulation of unhealthy behaviours was much less pronounced among non-smokers than among smokers. According to these authors, smoking may be a gateway to a wider range of adverse health behaviours (to an unhealthy lifestyle in general) (38). This implies that smokers are consistent in their unhealthy behaviours.

Our study proved that among randomly selected Polish adults (aged 18-66 yrs) socioeconomic risk factor associated with smoking among women was occupation. The lowest risk of smoking was found out among non-professional women, while female students were at the highest risk. This result is inconsistent with a previous study showing that being non-professional or manual worker increases the likelihood of smoking among European women (39). There are some explanations for these differences. The first, in study conducted by Davey Smith (39) current smokers were defined as individuals smoking at least one cigarette each day. In our study daily and occasionally smokers were included in category "smokers". The results of the bivariate relationships (the $\chi^{2}$ test) between smoking status and occupation (not presented here) have shown that female students smoked less intensively than other women, but there was the lowest percentage of non smokers among this sub-groups. Among non-professional the prevalence of non-smoking was the highest, but intensity of smoking was high. These tendencies are similar to these observed in the previous study (39). Because in logistic regression analyses we coded as smokers individuals occasionally and daily smoking, vs non smoking, female students were shown at the highest risk of smoking. The second, in our study female students were usually characterized by secondary education, living in the cities, and being single. In the crude analyses all these factors were shown as directly associated with smoking among women. The accumulation of three (not statistically significant) factors supporting smoking in the same person can perhaps explain the high risk of being a smoker observed among students.

In the present study this high risk of smoking was not documented among male students. We observed that among male students only "living in the cities" and being single were directly associated with smoking. What is more, contrary to women, being 
higher educated supported non-smoking behaviour among men. Moreover, the odds of smoking were lower among men living in the cities then among women living there. This result is consistent with the results of study conducted in Bulgaria (20). However, among men, no association was observed between smoking and level of urbanization in any of the Baltic countries (14). It is also possible that other, no measured in the present study, factors differed male and female students' smoking status. This hypothesis is supported by the results from the study of Polish medical students conducted with regard to the cigarette smoking habits. They have shown that the reasons for smoking - chiefly among female students - are stress and sociability (40).

The results of our survey documented that men with higher education were less likely to smoke compared to the less educated, but among Polish women smoking was more common among those with higher education. The result for men is consistent with the observations made in other studies conducted in several Western European countries (41), in the European Union countries (42), among men in Barcelona (43), among men in four Baltic countries (14) and Australia (44), and members of the middle class in Poland (46). Also in a national survey of Aboriginal and Torres Strait Islander people (Australia) higher socio-economic position (as measured by nine variables, including education) was strongly associated with being a non-smoker rather than a smoker, after controlling for age and gender (46). Whereas, the findings from the study of Bulgarian adults suggest that there is no significant association between smoking and education (20). However, among women in Bulgaria (20), in some West European countries (47), and in Barcelona (43) smoking is most common among those with secondary or higher education, which is consistent with our study.

There are several potential limitations to our study. First, we use self-reported data from questionnaires, which tend to over-report the actual level of physical activity (48), and underestimate or distortion alcohol consumption (49). Secondly, categories with the highest frequency of alcohol consumption had the fewest number of individuals, thus limiting our ability to comment on the relation of alcohol consumption to the prevalence of smoking. Third, we are aware the results may not necessary be representative of the overall population since the sample was randomly selected from telephone directories for the three provinces in which only about $76 \%$ of households have used standard main telephone line (50). Finally, we were not able to collect any information about nonrespondents. However, recent work has found that such worries may be exaggerated, because in general household population random digit-dialed surveys, response rates ranging from 30 to $70 \%$, were not associated with significant bias (51).

\section{CONCLUSION}

The findings of this study indicated that among randomly selected Polish man and women aged 18-66 smoking and alcohol consumption tended to cluster. These results imply that intervention strategies need to target multiple risk factors simultaneously. The highest risk of smoking were noticed among low educated men, female students, and both men and women drinking alcohol several times a week or every day. Information on subgroups with the high risk of smoking will help in planning future preventive strategies.

\section{REFERENCES}

1. U.S. Department of Health and Human Services. The health consequences of smoking: a report of the surgeon general. Atlanta: U.S. Department of Health and Human Services, Centers for Disease Control and Prevention, National Center for Chronic Disease Prevention and Health Promotion, Office on Smoking and Health; 2004.

2. Segovia J, Bartlett RF, Edwards AC. Health status and health practices - Alameda and beyond. Int J Epidemiol. 1991 Mar;20(1):259-63.

3. Luoto R, Prättälä R, Uutela A, Puska P. Impact of unhealthy behaviors on cardiovascular mortality in Finland, 1978-1993. Prev Med. 1998 JanFeb;27(1):93-100.

4. Meng L, Maskarinec G, Lee J, Kolonel LN. Lifestyle factors and chronic diseases: application of a composite risk index. Prev Med. 1999 Oct;29(4):296-304.

5. World Health Organization. Health 21: the health for all policy framework for the WHO European Region. European health fot all series no.6. Copenhagen: WHO Regional Office of Europe; 1999.

6. Watson P. Explaining rising mortality among men in eastern Europe. Soc Sci Med. 1995 Oct;41(7):923-34.

7. Peto R, Lopez AD, Boreham J, Thun M, Heath CJ. Mortality from smoking in developed countries 1950-2000: indirect estimates from national vital statistics. Oxford: Oxford University Press; 1994.

8. Central Statistical Office. Health status of Polish population in 2004. Warszaw: Zakład Wydawnictw Statystycznych; 2006. (In Polish.)

9. Kwaśniewska M, Kaczmarczyk-Chałas K. Health-related behaviours associated with smoking and nutrition in the representative sample of inhabitants of Łódź. "Bridging the East-West Health Gap" Project-Cindi 1996. In: Drygas W, Maniecka-Bryła I, Bryła M, editors. Advances in prevention and treatment of chronic non-infectious diseases. Łódź: 2000. p. 29-32. (In Polish.)

10. Laaksonen M, McAlister AL, Laatikainen T, Drygas W, Morava E, Nüssel E, et al. Do health behaviour and psychosocial risk factors explain the European east-west gap in health status? Eur J Public Health. 2001 Mar;11(1):65-73.

11. Łopuszańska M, Szklarska A, Jankowska EA. Health-related behaviours of Polish men and women in years 1984-1999. Zdrowie Publiczne. 2004;114(1):23-8. (In Polish.)

12. Centers for Disease Control and Prevention (CDC). Cigarette smoking among adults - United States, 2004. MMWR Morb Mortal Wkly Rep. 2005 Nov 11;54(44):1121-4.

13. Van der Wilk EA, Jansen J. Lifestyle-related risks: are trends in Europe converging? Public Health. 2005 Jan;119(1):55-66.

14. Helasoja VV, Lahelma E, Prättälä RS, Patja KM, Klumbiene J, Pudule I, et al. Determinants of daily smoking in Estonia, Latvia, Lithuania, and Finland in 1994-2002. Scand J Public Health. 2006;34(4):353-62.

15. Varo JJ, Martínez-González MA, De Irala-Estévez J, Kearney J, Gibney M, Martínez JA. Distribution and determinants of sedentary lifestyles in the European Union. Int J Epidemiol. 2003 Feb;32(1):138-46.

16. Peel NM, McClure RJ, Bartlett HP. Behavioral determinants of healthy aging. Am J Prev Med. 2005 Apr;28(3):298-304.

17. Kaczyński AT, Manske SR, Mannell RC, Grewal K. Smoking and physical activity: a systematic review. Am J Health Behav. 2008 JanFeb;32(1):93-110.

18. Sallis JF, Hovell MF, Hofstetter CR. Predictors of adoption and maintenance of vigorous physical activity in men and women. Prev Med. 1992 Mar;21(2):237-51

19. U.S. Department of Health and Human Services. Healthy people 2010: understanding and improving health. 2nd ed. Washington, DC: U.S. Government Printing Office; 2000.

20. Balabanova D, Bobak M, McKee M. Patterns of smoking in Bulgaria. Tob Control. 1998; 7(4):383-5.

21. De Leon J, Rendon DM, Baca-Garcia E, Aizpuru F, Gonzalez-Pinto A, Anitua C, et al. Association between smoking and alcohol use in the general population: stable and unstable odds ratios across two years in two different countries. Alcohol Alcohol. 2007 May-Jun;42(3):252-7.

22. Satre DD, Gordon NP, Weisner C. Alcohol consumption, medical conditions, and health behavior in older adults. Am J Health Behav. 2007 May-Jun;31(3):238-48.

23. McDermott L, Dobson A, Russell A. Changes in smoking behaviour among young women over life stage transitions. Aust N Z J Public Health. 2004 Aug;28(4):330-5.

24. French MT, Zavala SK. The health benefits of moderate drinking revisited: alcohol use and self-reported health status. Am J Health Promot. 2007 Jun-Aug;21(6):484-91. 
25. McElduff P, Dobson AJ. How much alcohol and how often? Population based case-control study of alcohol consumption and risk of a major coronary event. BMJ. 1997 Apr 19;314(7088):1159-64.

26. Gun RT, Pratt N, Ryan P, Gordon I, Roder D. Tobacco and alcohol-related mortality in men: estimates from the Australian cohort of petroleum industry workers. Aust N Z J Public Health. 2006 Aug;30(4):318-24.

27. Freiberg MS, Cabral HJ, Heeren TC, Vasan RS, Curtis Ellison R; Third National Health and Nutrition Examination Survey. Alcohol consumption and the prevalence of the metabolic syndrome in the U.S.: a crosssectional analysis of data from the Third National Health and Nutrition Examination Survey. Diabetes Care. 2004 Dec;27(12):2954-9.

28. Dufour MC. Risks and benefits of alcohol use over the life span. Alcohol Health Res World. 1996;20(3):145-51.

29. Hart CL, Smith GD, Hole DJ, Hawthorne VM. Alcohol consumption and mortality from all causes, coronary heart disease, and stroke: results from a prospective cohort study of Scottish men with 21 years of follow up. BMJ. 1999 Jun 26;318(7200):1725-9.

30. Steptoe A, Wardle J, Fuller R, Holte A, Justo J, Sanderman R, et al. Leisure-time physical exercise: prevalence, attitudinal correlates, and behavioral correlates among young Europeans from 21 countries. Prev Med. 1997 Nov-Dec;26(6):845-54.

31. Mensink GB, Loose N, Oomen CM. Physical activity and its association with other lifestyle factors. Eur J Epidemiol. 1997 Oct;13(7):771-8.

32. Shapo L, Pomerleau J, McKee M. Physical inactivity in a country in transition: a population-based survey in Tirana City, Albania. Scan J Public Health. 2004;32(1):60-7.

33. Zimmermann E, Ekholm O, Grønbæk M, Curtis T. Predictors of changes in physical activity in a prospective cohort study of the Danish adult population. Scand J Public Health. 2008 May;36(3):235-41.

34. Pitsavos C, Panagiotakos DB, Lentzas Y, Stefanadis C. Epidemiology of leisure-time physical activity in socio-demographic, lifestyle and psychological characteristics of men and women in Greece: the ATTICA Study. BMC Public Health. 2005 Apr 18;5:37.

35. Norman A, Bellocco R, Vaida F, Wolk A. Total physical activity in relation to age, body mass, health and other factors in a cohort of Swedish men. Int J Obes Relat Metab Disord. 2002 May;26(5):670-5.

36. Lee CY, Hwang SY, Ham OK. Factors associated with physical inactivity among Korean men and women. Am J Health Behav. 2007 SepOct;31(5):484-94

37. Kuński H. Smoking and physical activity. Magazyn Medyczny. 1996;7(12):47-9. (In Polish.)

38. Prättälä R, Karisto A, Berg MA. Consistency and variation in un- healthy behaviour among Finnish men, 1982-1990. Soc Sci Med. 1994 Jul;39(1):115-22.

39. Davey Smith G, Hart C, Hole D, MacKinnon P, Gillis C, Watt G, et al. Education and occupation social class: which is the more important indicator of mortality risk? J Epidemiol Community Health. 1998 Mar;52(3):153-60.

40. Kozielski J, Jastrzębski D, Gabryś J. Changes of smoking habits during 10 years in population of II year medical school students. Pneumol Alergol Pol. 1996;64(1-2):50-3. (In Polish.)

41. Giskes K, Kunst AE, Benach J, Borrell C, Costa G, Dahl E, et al. Trends in smoking behaviour between 1985 and 2000 in nine European countries by education. J Epidemiol Community Health. 2005 May;59(5):395-401.

42. Huisman M, Kunst AE, Mackenbach JP. Inequalities in the prevalence of smoking in the European Union: comparing education and income. Prev Med. 2005 Jun;40(6):756-64.

43. Borrel C, Dominguez-Berjón F, Pasarin MI, Ferrando J, Rohlfs I, Nebo $\mathrm{M}$. Social inequalities in health related behaviours in Barcelona. J Epidemiol Community Health. 2000 Jan;54(1):24-30.

44. Siahpush M, Borland R. Socio-demographic variations in smoking status among Australian aged $>$ or $=18$ : multivariate results from the $1995 \mathrm{Na}-$ tional Health Survey. Aust N Z J Public Health. 2001 Oct;25(5):438-42.

45. Borowiec A. Determinants of cigarettes smoking among members of middle class in Poland. Zdrowie Publiczne. 2007;117(1):25-31. (In Polish.)

46. Thomas DP, Briggs V, Anderson PS, Cunningham J. The social determinants of being an Indigenous non-smoker. Aust N Z J Public Health 2008 Apr;32(2):110-6. Erratum in: Aust N Z J Public Health. 2008 Jun;32(3):249.

47. Shafey O, Dolwick S, Guindon GE, editors. Tobacco control country profiles 2003. Atlanta: American Cancer Society; 2003.

48. Shephard RJ. Limits to the measurement of habitual physical activity by questionnaires. Br J Sports Med. 2003 Jun;37(3):197-206.

49. Embree BG, Whitehead PC. Validity and reliability of self-reported drinking behaviour: dealing with the problem of response bias. J Stud Alcohol. 1993 May;54(3):334-44.

50. Central Statistical Office. Life conditions of Polish population in 20042005. Warszaw: Zakład Wydawnictw Statystycznych; 2007. (In Polish.)

51. Keeter S, Miller C, Kohut A, Groves RM, Presser S. Consequences of reducing nonresponse in a national telephone survey. Public Opin Q. 2000;64(2):125-48.

Received September 24, 2009 Accepted in revised form September 6, 2010 